\title{
Sexual Dysfunctions as Self-Reported by Diabetic- Type- 2 Men: An Andrology Clinic-Based Study in Alexandria, Egypt
}

\author{
Nader Salama* \\ Department of Urology, Alexandria Faculty of Medicine, Alexandria, Egypt \\ *Corresponding author: nadersalama58@yahoo.com \\ Received April 16, 2013; Revised May 20, 2013; Accepted May 21, 2013
}

\begin{abstract}
Objectives: To document the prevalence of self-reported sexual dysfunctions (SDs) in diabetic type 2 (DM2) men attending the andrology clinic in the Alexandria University hospital. Methods: A retrospective analysis of clinical case records of 276 consecutive DM2 and 100 consecutive non-diabetic (controls) men who reported SDs directly to the andrology clinic was done. Results: The majority of the patients and controls had light manual occupation, low education level and no history of smoking. No patient reported history of alcohol intake. Erectile dysfunction (ED) was frequent in the DM2 patients and the only complaint in 54.7\%. The remaining patients had more than one (compound) complaint. ED (42.7\%), premature ejaculation (22.1\%) and low libido (11.7\%) were the most frequent SDs in these compound complaints. They often joined together in the patients. Less frequently reported SDs were anejaculation (7.2\%), penile curvature (4.4\%), small-sized penis (2.5\%) and penile plaques $(0.7 \%)$. Penile pain and delayed and painful ejaculations were the rarest reported SDs. Conclusion: DM2 men consulting the andrology clinic may present with several different sexual complaints although ED is the most frequent among these. All diabetic men, therefore, should be asked carefully about the probable existence of any variety of SDs during their medical evaluation.
\end{abstract}

Keywords: diabetes, sexual dysfunction, self-reported complaints

\section{Introduction}

Diabetes is a chronic metabolic disorder capable of affecting multiple organ systems. In 2003, Egypt was included in the world's top ten in terms of the greatest number of people with diabetes. The number of diabetic Egyptians reached 3.9 million during that year, that is, $5.2 \%$ of the population of Egypt [1]. It is expected that this number will increase to range between $14-20 \%$ in 2025 [2]. Alexandria prefecture, with the prevalence of diabetes at $8 \%$, has the second highest prevalence of diabetes among other Egyptian prefectures [1]. Diabetes is commonly associated with several sexual dysfunctions (SDs) $[3,4]$. Therefore, it is supposed that a significant number of Egyptian men with diabetes will suffer from different SDs. In spite of this, talking about sexual matter in the Egyptian community is still a taboo which makes hard to unveil the characteristic features of many SDs. There is a paucity of literature on SDs, other than erectile dysfunction, in Egyptian males.

Erectile dysfunction (ED) is the most frequent SD associated with diabetes $[3,5,6]$. This well recognized association is secondary to several diabetes-induced pathophysiological mechanisms. Among these detrimental mechanisms are diabetic microangiopathy, autonomic neuropathy, hypogonadism as well as psychological disorders [7,8,9,10]. Diabetic ED has received an enormous amount of interest while little attention has been paid to other sexual problems in diabetic men. Only a few studies have reported the prevalence of other SDs in diabetic men like premature ejaculation $[3,11,12]$ and low libido $[3,13,14]$ but the prevalence, demographics, risk factors and pathogenesis of these problems are still not well addressed yet. On the other hand, SDs, like delayed and retrograde ejaculations have scarcely been described [15].

Non-erectile SDs may cause troubles in the couple relationships, and become very distressing to the patients. Consequently, depression and diminished quality of life will be an expected end result [16]. This situation seems similar to what could be happening during the course of ED [17], if not higher in severity. Therefore, the aim of this work was to highlight the different SDs among DM2 men attending the andrology clinic in the Alexandria University General Hospital, report their prevalence and describe the socio-demographic characteristics of the patients.

\section{Patients and Methods}

\subsection{Study Type and Subjects}

Retrospective review of 276 consecutive DM2 men who presented with complaints of sexual dysfunction at in the Alexandria University General Hospital in Alexandria, 
Egypt was undertaken. A control group consisting of 100 consecutive non-diabetic patients who consulted the clinic during the same time period were enrolled. The study was approved by the Departmental Research Committee. According to the policy of the Alexandria University General Hospital, a written consent is usually taken from each patient once he/she comes seeking for medical advice in order to use his/her data for any future research purposes.

\subsection{Exclusion Criteria}

Patients under testosterone replacement therapy for previously diagnosed hypogonadism, or those with renal insufficiency, hepatic impairment, major psychiatric disorders or chronic debilitating diseases were excluded from the study. Patients were also excluded if they were not engaged in steady heterosexual activity.

\subsection{Data Collection}

Data were collected from patients' records. Study variables included socio-demographic features as age, occupation, education level, marital status \& body mass index (BMI). Retrieved data also incorporated past, drug (history of substance or drug-abuse which could be capable of affecting the sexual function) \& family detailed histories, and any alcohol intake or smoking habits together with physical examination. Number of sexual episodes/ week, number of partners with last 6 months of referral and sex out of marriage were retrieved from patients' files.

Sexual complaints were collected as self-reported by the study patients, and documented in the recording system by the same physician. For $E D$, it was documented in the study when it was continuing over duration of at least 3 months with the patient in a steady heterosexual relation. It was assessed by the abridged 5-item version of the International Index of Erectile Function [18] whose Arabic version was already prepared [19]. Premature ejaculation (PE) was diagnosed according to AUA guidelines [20] and using the Diagnostic and Statistical Manual of Mental Disorders, 4th Edition- text revision (DSM-IV-TR) classification [21] as "ejaculation that occurred sooner than desired either before or shortly after penetration causing distress to either one or both partners". Delayed ejaculation was present when the man's orgasm was persistently or repeatedly delayed or absent after enough time of erotic stimulation causing marked distress or interpersonal difficulty [21]. Libido was assessed by asking patients to grade their desire for sexual activity as either good, fair or reduced.

Data from laboratory evaluation were retrieved. As a routine practice in our andrology clinic, laboratory determinations included complete blood count, serum total testosterone, prolactin and blood sugar (fasting/random). In patients with already documented history of diabetes, HbA1c was estimated. Semen and urine cultures were requested in cases of suspected genital infection. Examination of urine after masturbation for presence of sperms was done in patients with absent ejaculate to rule out retrograde ejaculation.

Penile length measurement was always done while doing intra-corporal injection to check for penile curvature (PC) with photography of the organ or as a preliminary step to do penile duplex scanning in cases of ED evaluation. The later situation was especially useful in cases complaining of a decrease in penile length of a recent onset as this was suggestive of the probable existence of Peyronie`s disease (PD). In cases of alleged small sized penis (SSP) where the patients believed their problem to be genuine in nature, penile length measurement was done after full stretching of the organ.

\subsection{Statistical Analysis}

The raised data were analyzed using SPSS statistical software for Windows Release 16 (SPSS Inc., Chicago, USA) on a personal computer. Descriptive statistics (mean and standard deviation) were done for all demographic variables. Frequency showing prevalence of different SDs were also expressed according to the number of presenting patients. The socio-demographics of the patients were compared with those of the controls to see the distribution of SDs among the study participants and judge the impact of diabetes on SD using independent T-, Mann-Whitney and Chi-square tests. The effect of the diabetes durations and HbA1c levels of the patients on the number of reported SDs was examined using Kruskal Wallis test. Correlation between severity of ED as assessed by IIEF-5 and BMI or HbA1c was done using Pearson rank correlation coefficient (r). P-value $(<0.05)$ was considered significant.

\section{Results}

\subsection{Patients}

Two hundred seventy six consecutive DM2 patients aged (50.02 y \pm 9.02), and 100 non-diabetic patients (controls) aged (38.49 $\mathrm{y} \pm 13.55, \mathrm{p}<0.001)$ were retrieved. All DM2 patients had documented history of diabetes with duration (9.9 y \pm 6.4), and were under anti-diabetic medical treatment. Their HbA1c levels were 10.5\% \pm 2.4 and random blood sugar readings were $246.3 \mathrm{mg} \% \pm 73.3$. Testosterone results were $3.8 \mathrm{ng} / \mathrm{mL} \pm 1.7$ for the patients and $3.8 \mathrm{ng} / \mathrm{mL} \pm 1.5$ for the controls with no significant difference $(\mathrm{p}=0.79)$. BMI of the patients was significantly higher than that of the controls $(29.3 \pm 7$ vs $27.5 \pm 4.4$, Table 1). Table 1 shows also that the majority of these patients were $\geq 50$ y old and had $\mathrm{HbA} 1 \mathrm{c}>7 \%$ in contrast to controls who were mostly $<50 \mathrm{y}$ old. In addition, the majority of the study patients and controls were over weighted. They had class 3 (light manual) occupation, low education level and no history of smoking. Self-reported alcohol intake was nil. There was significant difference between both study groups as regard marital status but not in relation to sex episodes/week. All the patients and controls enrolled in this study were circumcised since early childhood as they all were muslims. The preputal skin was nicely cut. There was no excess skin removed or left behind. There was also no cases with penile rotation.

\subsection{Sexual Dysfunctions}

\subsubsection{Grouping}

According to the number of the self-reported SDs, given by each participant in the current study, all 
participants were arranged into 3 subgroups with one, two or three reported SD (s) (Table 2 \& Table 3). The participants in the groups with $>$ one (multiple) reported SDs used to express a deeper concern about a certain problem compared with their other problems. We called this distressing problem, the main problem (Table 3). The durations of complaints with the single SDs and the main problem among the multiple SDs were 3m - 25y (3.02 y \pm 3.34) for the patients and 3m-22y (4 y \pm 4.7 ) for the controls with no significant difference $(p=0.13)$ in between. Data analysis showed also no significant differences among durations of DM \& HbA1c readings of the different patient groups (Table 4). No female partner accompanied her husband when he presented to the clinic.

Table 1. Sociodemographics of the study DM2 patients $(n=276)$ and controls $(n=100)$

\begin{tabular}{|c|c|c|c|c|}
\hline Sociodemographic variable & Types & $\begin{array}{c}\text { DM2 Patient No. } \\
(\%)\end{array}$ & Controls No. (\%) & p-value \\
\hline Age & $\begin{array}{l}<50 y \\
\geq 50 y\end{array}$ & $\begin{array}{l}109(39.5) \\
167(60.5)\end{array}$ & $\begin{array}{l}81(81) \\
19(19)\end{array}$ & $<0.001^{* *}$ \\
\hline HbA1c & $\begin{array}{l}\leq 7 \% \\
>7 \% \\
\end{array}$ & $\begin{array}{c}15(6.6) \\
211(93.4) \\
\end{array}$ & & \\
\hline BMI & $\begin{array}{c}\text { Normal } \\
\text { Overweight } \\
\text { Obese } 1 \\
\text { Obese } 2 \\
\text { Morbid obesity }\end{array}$ & $\begin{array}{c}32(22.5) \\
59(41.6) \\
35(24.7) \\
6(4.2) \\
10(7)\end{array}$ & $\begin{array}{c}2(2.2) \\
62(68.9) \\
21(23.3) \\
5(5.6) \\
0(0)\end{array}$ & $=0.025^{* *}$ \\
\hline Education (y) & $\begin{array}{c}\text { Before high school } \\
\text { High school } \\
\text { University }\end{array}$ & $\begin{array}{l}153(60.5) \\
74(29.2) \\
26(10.3) \\
\end{array}$ & $\begin{array}{l}40(51.3) \\
20(25.6) \\
18(23.1) \\
\end{array}$ & $<0.001 *$ \\
\hline Occupation & $\begin{array}{c}\text { Class } 2 \\
\text { Class } 3 \\
\text { Class } 4 \\
\text { Home }\end{array}$ & $\begin{array}{c}6(2.2) \\
181(67.6) \\
70(26.1) \\
11(4.1)\end{array}$ & $\begin{array}{c}2(2.6) \\
49(62.8) \\
20(25.6) \\
7(9)\end{array}$ & $=0.93^{*}$ \\
\hline Marital status & $\begin{array}{c}\text { One wife } \\
\text { Two wives } \\
>\text { Two wives } \\
\text { Single } \\
\text { Divorced }\end{array}$ & $\begin{array}{c}234(84.7) \\
29(7.6) \\
9(3.3) \\
2(0.7) \\
2(0.7)\end{array}$ & $\begin{array}{c}77(77) \\
9(9) \\
- \\
10(10) \\
4(4)\end{array}$ & $<0.05^{* * *}$ \\
\hline Sex episodes/week & & 1.4 & 2.1 & $0.063^{* *}$ \\
\hline Smoking & $\begin{array}{c}\text { Smoker } \\
\text { Ex-smoker } \\
\text { Non-smoker }\end{array}$ & $\begin{array}{c}64(23.2) \\
9(3.3) \\
203(73.5) \\
\end{array}$ & $\begin{array}{c}25(25) \\
0(0) \\
75(75)\end{array}$ & $<0.05^{* * *}$ \\
\hline
\end{tabular}

Data were not available for HbA1c, BMI, education level and occupation in 50, 134, 23\& 8 patients; respectively, and for education, occupation, BMI in 22, 22, 10 controls. The percentage values of these variables as indicated in the table, therefore, represent 226, $142,253 \& 268$ patients and $78,78,90$ controls; respectively.

*Mann-Whitney test, ** Independent T-test, *** Chi Square test

Table 2. Prevalence of single SD complaint as reported by the study DM2 patients and controls

\begin{tabular}{|c|c|c|}
\hline \multicolumn{1}{|c|}{ Table 2. Prevalence of single SD complaint as reported by the study DM2 patients and controls } & Non-diabetic patients (\%) \\
\hline Patient number/group & $153(55.43)$ & $151(54.71)$ \\
\hline ED & $1(0.36)$ & $41(41)$ \\
\hline Premature ejaculation & $1(0.36)$ & $2(2)$ \\
\hline Low libido & - & $9(9)$ \\
\hline Small-sized penis & - & $1(1)$ \\
\hline
\end{tabular}

-the prevalence of each SD complaint was calculated in relation to the total number of the study patients (276) and (100) controls.

\subsubsection{Frequency \& Ranking}

ED was accounted by almost all the patients and controls (Table 2 and Table 3). Table 3 shows that disorders of ejaculation combined with ED came as the most frequent combination of self-reported SDs in the patient and control subgroups with 2 SDs. In the patient subgroup with 3 SDs, low libido (LL) joined this combined association of ED and ejaculation disorders to keep it as the most frequent consultation by the patients of this subgroup while alleged SSP joined the same combination in place of LL in the controls. Therefore, disorders of ejaculation occupied the second rank in the list of the reported SDs after ED in either the patient or control groups. Then, this was followed by LL in the patient group but alleged SSP in the control group (Table 5). In the patient group, $\mathrm{PE}$ came as the most frequent disorder inside the spectrum of ejaculation disorders followed by absent ejaculation. The latter was accounted to be related to retrograde ejaculation as shown by the presence of sperms in post-masturbation urine. Painful ejaculation was the least frequent complaint inside this group (Table 5). In the control group, PE was the only ejaculation problem accounted by the participants. Table 5 showed also that ED was more prevalent in the diabetic patients while PE, LL and alleged SSP were more prevalent in the non-diabetic controls. 
Table 3. Combination patterns of different SDs as reported by the 2 SDs subgroup (110 patients/35 controls) \& 3 SDs subgroup (13 patients/7 controls)

\begin{tabular}{|c|c|c|}
\hline Type of sexual dysfunction & DM2 Patient no. (\%) & $\begin{array}{c}\text { Control no. } \\
\text { (\%) }\end{array}$ \\
\hline 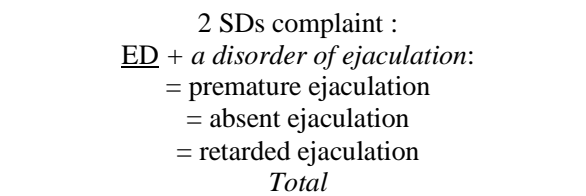 & $\begin{array}{l}51(18.48) \\
19(6.88) \\
1(0.36) \\
71(25.72)\end{array}$ & $\begin{array}{c}21(21) \\
- \\
-\end{array}$ \\
\hline $\begin{array}{c}\underline{\mathrm{ED}}+\text { a disorder of penile image: } \\
=\mathrm{SSP} \\
=\mathrm{PC} \\
=\text { penile plaques } \\
\text { Total }\end{array}$ & $\begin{array}{l}2(0.73)-\mathrm{r} \\
7(2.6) \\
2(0.73) \\
11(4.06)\end{array}$ & $\begin{array}{l}3(3) \\
- \\
- \\
-\end{array}$ \\
\hline $\begin{array}{c}\underline{\mathrm{ED}}+\text { another complaint: } \\
=\text { low libido } \\
=\text { penile pain with erection } \\
\text { Total }\end{array}$ & $\begin{array}{c}25(9.06) \\
1(0.36) \\
26(9.42)\end{array}$ & $\begin{array}{c}6(6) \\
- \\
-\end{array}$ \\
\hline $\begin{array}{c}\underline{\text { low libido }}+\text { premature ejaculation } \\
\underline{\text { PC }+ \text { SSP }} \\
\text { premature ejaculation }+ \text { PC } \\
\underline{\text { SSP }+ \text { premature ejaculation }}\end{array}$ & $\begin{array}{l}1(0.36) \\
1(0.36) \\
- \\
-\end{array}$ & $\begin{array}{l}2(2) \\
- \\
1(1) \\
2(2)\end{array}$ \\
\hline 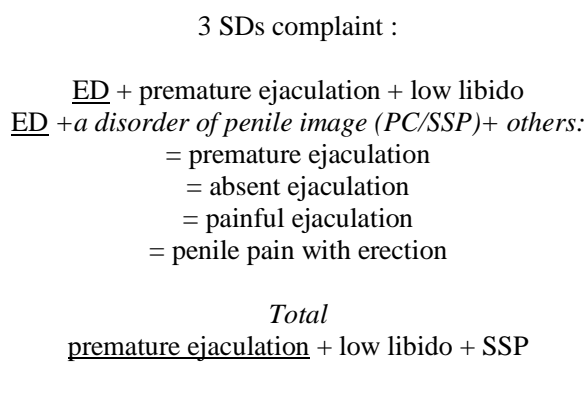 & $\begin{array}{c}6(2.2) \\
\\
3(1.1) \\
1(0.36) \\
2(0.73) \\
1(0.36) \\
7(2.6)-\mathrm{r} \\
-\end{array}$ & $\begin{array}{l}3(3) \\
3(3)\end{array}$ \\
\hline
\end{tabular}

- The main complaint among these multiple-component complaints was underlined.

- ED: erectile dysfunction; PC: penile curvature; SSP: small-sized penis; -r: recent onset

There is one non-diabetic control who had 4 SDs complaint (ED, PE, SSP, PC).

Table 4. Grouping of the HbA1c levels \& diabetes duration of the study patients according to the number of reported SDs *

\begin{tabular}{|c|c|c|c|c|c|}
\hline \multirow{2}{*}{$p=0.17$} & HbA1c & $\begin{array}{c}\text { Patient } \\
\text { No.\# }\end{array}$ & $\begin{array}{c}\text { No. of } \\
\text { reported SDs }\end{array}$ & Patient No.\# & $\begin{array}{c}\text { DM } \\
\text { duration (y) }\end{array}$ \\
\cline { 3 - 7 } & $10.3 \pm 2.6$ & 125 & 1 & 153 & $10.1 \pm 6.7$ \\
\cline { 3 - 7 } & $10.8 \pm 2.3$ & 88 & 2 & 109 & $9.7 \pm 5.9$ \\
\cline { 3 - 7 } & $10 \pm 1.9$ & 13 & 3 & 14 & $8.7 \pm 6.2$ \\
\hline
\end{tabular}

*Kruskal Wallis test

\# Patient No. with available data

Table 5. Ranking of SDs as reported by the study patients and controls

\begin{tabular}{|c|c|c|c|}
\hline \multirow{2}{*}{ Reported SD } & \multicolumn{2}{|c|}{ Total reports (\%) in the whole } & \multirow{2}{*}{ s-value } \\
\cline { 2 - 3 } & DM2 patients & Controls & \multirow{2}{*}{ - valy } \\
\hline Patient number/group & 276 & 100 & \\
\hline ED & $271(98.19)$ & $78(78)$ & $<0.001$ \\
\hline Premature ejaculation & $62(22.46)$ & $38(38)$ & $<0.001$ \\
\hline Absent ejaculation & $20(7.24)$ & - & \\
\hline Delayed ejaculation & $1(0.36)$ & - & \\
\hline Painful ejaculation & $2(0.73)$ & - & \\
\hline Low libido & $33(11.95)$ & $14(14)$ & $<0.001$ \\
\hline Penile curvature & $12(4.35)$ & $2(2)$ & $<0.001$ \\
\hline Small-sized penis & $6(2.18)-r$ & $18(18)$ & $<0.001$ \\
\hline Penile plaque & $2(0.73)$ & - & \\
\hline Pain during erection & $2(0.73)$ & $1(1)$ & Not done \\
\hline
\end{tabular}

-r: recent onset

Disorders of penile image took the fourth position in the list of the self-reported SDs in the patient group (Table 5). Table 3 shows that these disorders came in combination with different SDs but mainly with ED. PC, as confirmed by photography of the penis while erected, was the commonest reported penile image disorder while pain during erection was the least one. Reports about penile image abnormalities of recent onset like PC and decrease in penile length which was frequently called by the patients as small-sized penis, were suggestive of PD. In addition, these patients presented also with penile plaques and pain during erection. The total number of patients with these disorders was 19 (6.9\%) patients. Painful (prostatitis, confirmed with bacteriological examination) and delayed ejaculations were the rarest reported SDs (Table 3). In contrast, disorders of penile image had the third rank while LL occupied the fourth rank in the control group. The penile image disorders included only alleged SSP and genuine PC with no reporting about $\mathrm{PD}$. 


\subsubsection{Independent Variables with SDs}

In DM2 patients with ED, there were no correlation between IIEF-5 scores and either HbA1c $(r=0.17, p=0.38)$ or BMI ( $\mathrm{r}=0.094, \mathrm{p}=0.4)$. The IIEF-5 scores in the patient group were significantly lower than those of the controls (10.2 \pm 4.3 vs $13.8 \pm 5.3$, $\mathrm{p}=0.000)$. Both age and BMI in the patient group were also significantly higher than those in the control group ( $\mathrm{p}=0.000,0.025$; respectively).

The same was also repeated with PE and LL. So, the diabetic patients suffering from $\mathrm{PE}$ or $\mathrm{LL}$ were significantly older than the controls (49.1 y \pm 8.7 vs $39.6 \mathrm{y}$ $\pm 11.2, \mathrm{p}=0.000$; in $\mathrm{PE}$ and $49.7 \pm 7.9$ vs $39.9 \mathrm{y} \pm 8.9$, $\mathrm{p}=0.000$; in LL). The BMI of the diabetic patients (31.3 \pm 10.8 in $\mathrm{PE}$ and $33 \pm 10.9$ in LL) were higher than those of the controls ( $28.1 \pm 4.1$ in PE and $28 \pm 3.8$ in LL) but with no significant difference ( $\mathrm{p}=0.18,0.14$; respectively).

\subsection{Penile Length and Circumference Measurement}

Men complaining of SSP not related to PD were 18 ., and belonged to the controls $\backslash$ group only. They had normal penile length and mid-shaft circumference as detected by penile measurements (data not shown). These cases with alleged SSP were the youngest (30.7 $\mathrm{y} \pm 9.3$ vs $40.2 \mathrm{y} \pm 13.8)$ among the other members of the control group. Among these 18 cases, 12 were single and 7 of these declared involving in steady sexual relations.

\section{Discussion}

In Egypt, there is still a significant lack of studies reporting the prevalence of different SDs. DM is a medical problem which has its great implications on male sexual function $[3,4]$. The current study is a retrospective survey which evaluated the prevalence of different SDs as selfreported by a cohort of diabetic men who consulted directly an andrology public clinic. So, problems of selection bias were greatly declined. To the best of our knowledge, this is the first study from Egypt and the Middle East reporting prevalence of different forms of SDs at the same time and in the same cohort of diabetic men.

Several demographic factors can play a fundamental role in psychopathology of SDs. In the present study, the majority of participants with available data were either overweight or obese while $26.5 \%$ were ex- or present smokers. It is well known that both body weight and smoking habit represent important risk factors for development of SD [22,23]. The participants had also lower level of education and were manual workers (class 3). This comes in line with several workers who demonstrated the same demographics in men with several SDs [11,24].

Self-reported complaints given by the study patients covered a big spectrum of SDs. Nearly half the patients $(44.57 \%)$ in the present work had more than one complaint. ED was the most common SD seen in the present study. It was either reported as a sole complaint or in combination with other complaints; giving an overall prevalence of $98.2 \%$. This high prevalence of ED in the current study patients can be attributed partly to the old age and poor glycemic control of a big sector of the patients. About $60 \%$ and $93.4 \%$ of these patients were $\geq 50$ y old and had $>7 \%$ HbA1c respectively. The current study, therefore, reconfirmed the high prevalence of ED among diabetic men with advancement of age [25] and with abnormal glycemic control [10]. In the current study, we did not find any correlation between either BMI or HbA1c and severity of ED based on IIEF-5. This may be related to non-adjustment of both variables for age as some studies did [26]. However, this agrees with some workers who showed lack of correlation between both variables and ED degree [27]. At that same time, the current study indicated that both age and BMI were significantly higher with diabetic ED than with non-diabetic ED. Both represent important risk factors for development of ED; particularly that associated with diabetes [8]. The current study showed also that severity of diabetic ED was significantly higher than that of non-diabetic ED. Diabetic ED is related to a multi-factorial process which fundamentally results from organic causes including diabetes-induced vasculogenic and neurogenic disorders, incidental medical diseases in diabetic patients and potential side effects of medications used by these patients $[8,28]$.

Premature ejaculation was the second most common SD (22.46\%) described by the study patients. It was almost always joining ED. This co-morbid PE and ED was also accounted by previous studies [29]. However, the prevalence of PE in the current study seems to be different than that documented by other self-reporting studies dealing with diabetic men. So, it was higher $(22.46 \%$ vs $6.2 \%$ ) than that reported by some authors like Basile Fasolo and his colleagues [12]. Those authors attributed their reported low prevalence to non-assignment of many of their diabetic patients to have $\mathrm{PE}$ as they were not engaged in steady sexual relations. On the other hand, it was lower ( $22.46 \%$ vs $40.2 \%$ ) than that demonstrated in 2 studies $[3,11]$. This difference may be related not only to the differences in duration of diabetes and the degree of success of its metabolic control but also to the ethnic difference of the studied patients in the different studies and lack of knowledge about norms in ejaculation capability among men in the current study. In addition, it is important to note that the prevalence of $\mathrm{PE}$ in the diabetic men reported in either studies $[3,11]$ was an exact copy (40.2\%) although the materials revealing this common prevalence were different. In the first study authorized by El-Sakka [11], the material consisted only of the acquired cases of PE which started after diagnosis of diabetes. In the second study published by Malavige et al. [3], the material included diabetic men with both acquired and life-long PE. The pathophysiology of premature ejaculation associated with diabetes is not clearly understood. It may be related to depression and anxiety which are observed in many diabetics [30], diabetic autonomic neuropathy [31] or drop in level of testosterone which is frequently associated with diabetes [32]. In the current study, the prevalence of PE was lower in diabetic group than the control one. This came in contrast with other workers [33] who indicated higher prevalence of PE in diabetic than general population. We can attribute our finding to the presence of many young men in the control group as single and their involvement in steady sexual relations which are considered in this community as illegal and sin. These relations are usually done in secret. This might put these men under stress 
pushing them to ejaculate rapidly. For this reason, age of the controls with PE was significantly younger than that of diabetic men with the same problem. On the other hand, $\mathrm{BMI}$ was higher in diabetic men with $\mathrm{PE}$ compared to that of the controls although the difference was insignificant. BMI was reported to be a risk factor for PE [11]. These findings related to higher prevalence of PE among the controls in the current study and their younger age and lower BMI were exactly seen during evaluation of LL in the current study, and could be explained on the same basis.

In the current study, the overall prevalence of LL was about $12 \%$. This was lower than that reported by other workers $(25.3 \%, 29.6,55.7 \% \%)$ [3,13,14]. This may be related to the existence of several differences between our Egyptian population and others. The difference in prevalence of reduced libido between different populations was previously documented in a communitybased study which showed that low sexual desire was more frequently reported by Japanese than American men [34]. Beside the ethnic differences, several factors which have an important influence on male sexual desire in diabetes should be considered among different studied populations. Examples of these may be again related to potential side effects of several medications used by those diabetic men, the change in lifestyle pattern of these men once they were diagnosed with diabetes, the psychological alterations associated with diabetes which have its impact on the patients' moods together with the attitude of their wives towards the disease $[8,13]$, and finally the androgen derangement in diabetes $[7,9,32]$ which has its positive correlation with libido [35,36]. However, there was no significant difference between diabetic patients and nondiabetic controls in the current study. Exactly like PE, LL was usually reported in association with other sexual complaints; typically ED in our diabetic patients. An interesting finding in the current study was that if the diabetic patient reported ED-LL compound complaint and wished to add further problems, the next complaint was always PE. This finding comes in accord with other studies [3.5] about the frequent concomitant presence of ED, PE, and LL among diabetic men. However, this triad of reported SDs was not seen in the controls as complaining of SSP replaced the complaint of LL.

The prevalence of absent ejaculate due to different causes and mechanisms is not thoroughly reported whether among diabetics or general population. In the current study, absent ejaculate reported by 20 (7.24\%) patients was attributed to retrograde ejaculation. This prevalence of retrograde ejaculation seems similar to that reported by other investigators [15]. The cause of the diabetic retrograde ejaculation is usually related to diabetic autonomic neuropathy which may cause dysfunction of bladder internal sphincter leading to retrograde ejaculation, and inhibition of seminal emission [37].

In the current study, patients' complaints about existence of penile plaques, pain during erection and a recent curvature in penile shaft or decrease in penile length were related to PD as confirmed clinically and on penile sonograms. The presence of penile plaques and recent penile curvature were similarly reported by diabetic patients with PD in previous studies $[38,39]$. Diabetes aggravates the pathogenesis of PD. It induces change of extracellular matrix metabolism in penile tissue with its deposition in tunica. This may constitute a possible mechanism for the high prevalence of PD in diabetes [40]. In the current study and according to the self-reporting by 19 patients, the prevalence of PD was 6.9\%. This agrees with that reported previously by several workers in a similar topic. So, El-Sakka \& Tayeb [24] in their study showed this prevalence to be $8.1 \%$ while Tefekli \& his colleagues [38] indicated it to be $10.7 \%$. In contrast to the diabetic group where complaining of SSP was of organic nature and of recent onset, all control members with this complain showed normal penile measurements with no detectable abnormalities during genital examination. These controls were always seeing their organs as small since early childhood. This agrees with Mondiani et al [41] who reported that most men seeking penile lengthening procedures have normal penile measurements. The majority of these men with alleged SSP in the current study were single and they were probably affected by what they heard from friends, media or their sexual partners about false ideas related to penile measurements and how it is significantly correlated with adequate erectile function and ability to conceive.

In the present study, only one patient presented with delayed ejaculation. His slow onset ejaculation did not reach the severe degree with total absence of ejaculation. In the literature, no studies investigated this problem among diabetic men, so far. Therefore, the real prevalence of delayed ejaculation it is still difficult to be defined. Even in general population, remarkably scarce studies investigated this problem. So, Corona et al [42] reported it among 62 of 1632 (3.8\%) men while Rowland et al [43] claimed it to be present in $2 \%$ among 1400 men.

Some limitations are present in the current study. One of these limitations is the partially missed data in some variables; a feature characteristic of many retrospective studies. However, we did not use such variables, except HbA1c, to make correlation with the different study points. This does not influence the final conclusion of the study. Another limitation was related to PE which was accounted depending on the patient's self-report, and not on defined tools to quantify this complaint like the index of premature ejaculation [44].

In conclusion, diabetic Egyptian patients consulting the andrology clinic reported several sexual complaints in different combinations but ED was the most frequent one. All men with DM, therefore, should be asked carefully about the probable existence of any variety of SD during their medical evaluation not focusing only on ED. This is supposed to help in early diagnosis and treatment of these sexual problems and thus keeping good couple relation. This can also be facilitated with open discussion about sexuality in the community in order to stop it as a taboo matter. This is supposed to help those men who are seeking medical sexual advice away from their partners. At the same time, the study still needs to be substantiated in a larger cohort and with more defined diagnostic tools to corroborate the current data.

\section{Acknowledgement}

Conflict of Interest: not present.

Sources of Funding : not present 
A master table containing the retrieved data of this study is documented, certified and saved at the Department of Urology, Alexandria Faculty of Medicine, Alexandria, Egypt.

\section{Statement of authorship}

Nader Salama : Conception and design of the study, collection, analysis and interpretation of data, and drafting the article with final approval of its completed form.

\section{References}

[1] Arafa, N., Amin, G. "Epidemiology of diabetes mellitus in Egypt: results of a national survey”. Egypt. J. Comm. Med. 28. 29-43. 2010.

[2] Diabetes Atlas. Third edition, International Diabetes Federation. 2006.

[3] Malavige, L.S., Jayaratne, S.D., Kathriarachchi, S.T., Sivayogan, S., Fernando, D.J., Levy, J.C. "Erectile dysfunction among men with diabetes is strongly associated with premature ejaculation and reduced libido”. J. Sex. Med. 5. 2125-2134. 2008.

[4] Isidro, M.L. "Sexual dysfunction in men with type 2 diabetes". Postgrad. Med J. 88,152-159. 2012.

[5] Malavige, L.S., Wijesekara, P., Seneviratne Epa, D., Ranasinghe, P., Levy. J.C. "Ethnic Differences in Sexual Dysfunction among Diabetic and Nondiabetic Males: The Oxford Sexual Dysfunction Study”. J. Sex. Med. 2012. Aug 27. 2012.

[6] Yamada, T., Hara, K., Umematsu, H., Suzuki, R., Kadowaki, T. "Erectile dysfunction and cardiovascular events in diabetic men: a meta-analysis of observational studies.” PLoS One [Accessed Sep 4, 2012].

[7] Barrett-Connor, E., Khaw, K.T., Yen, S.S. "Endogenous sex hormone levels in older adult men with diabetes mellitus". Am. J. Epidemiol. 132. 895-901. 1990.

[8] Minhas, S., Eardley, I. "Diabetic impotence”. In: Carson CK, Kirby R, Goldstein I, eds. Textbook of Erectile Dysfunction. Isis Medical Media, Oxford, 541-550. 1999.

[9] Tan, R.S., Pu, S.J. "Impact of obesity on hypogonadism in the andropause”. Int. J. Androl. 25. 195-201. 2002.

[10] Malavige, L.S., Levy, J.C. "Erectile dysfunction in diabetes mellitus”. J. Sex. Med. 6. 1232-1247. 2009.

[11] El-Sakka, A.I. "Premature ejaculation in non-insulin-dependent diabetic patients”. Int. J. Androl. 26. 329-334. 2003.

[12] Basile Fasolo, C., Mirone, V., Gentile, V., Parazzini, F., Ricci, E. "Premature ejaculation: Prevalence and associated conditions in a sample of 12,558 men attending the andrology prevention week 2001-A study of the Italian Society of Andrology (SIA)”. J. Sex. Med. 2. 376-382. 2005.

[13] Corona, G., Mannucci, E., Mansani, R., Petrone, L., Bartolini, M., Giommi, R., et al. "Organic, relational and psychological factors in erectile dysfunction in men with diabetes mellitus". Eur. Urol. 46. 222-228. 2004

[14] Nakanishi, S., Yamane, K., Kamei, N., Okubo, M., Kohno, N. "Erectile dysfunction is strongly linked with decreased libido in diabetic men”. Aging Male, 7. 113-119. 2004.

[15] Sexton, W.J., Jarow, J.P. "Effect of diabetes mellitus upon male reproductive function”. Urology. 49. 508-513. 1997.

[16] Symonds, T., Roblin, D., Hart, K., Althof, S. "How Does Premature Ejaculation Impact a Man’s Life?” J. Sex Mar. Ther. 29. 361-370. 2003.

[17] Mallis, D., Moisidis, K., Kirana, P.S., Papaharitou, S., Simos, G., Hatzichristou, D. "Moderate and severe erectile dysfunction equally affects life satisfaction”. J. Sex. Med. 3.442-449.2006.

[18] Rosen, R.C., Cappelleri, J.C., Smith, M.D., Lipsky, J., Pena, BM. "Development and evaluation of an abridged, 5-item version of the International Index of Erectile Function (IIEF-5) as a diagnostic tool for erectile dysfunction”. Int.J. Impotence Res. 11. 319-26. 1999.

[19] Shamloul, R., Ghanem, H., Abou-zeid, A. "Validity of the Arabic version of the sexual health inventory for men among Egyptians”. Int. J. Impotence Res. 16. 452-455. 2004.

[20] Montague, D.K., Jarow, J., Broderick, G.A., Dmochowski, R.R., Heaton, J.P., Lue, T.F., et al. "AUA guideline on the pharmacologic management of premature ejaculation”. J. Urol.172. 290-294. 2004
[21] American Psychiatric Association. "Diagnostic and Statistical Manual of Mental Disorders”. 4th ed, text revision. American Psychiatric Association,Washington, DC. 2000.

[22] Papaharitou, S., Athanasiadis, L., Nakopoulou, E., Kirana, P., Portseli, A., Iraklidou, M., et al. "Erectile dysfunction and premature ejaculation are the most frequently self-reported sexual concerns: profiles of 9,536 men calling a helpline”. Eur. Urol. 49, 557-63. 2006.

[23] Son, H., Song, S.H., Kim, S.W., Paick, J.S. "Self-reported premature ejaculation prevalence and characteristics in Korean yo ung males: community-based data from an internet survey". $J$. Androl. 31. 540-546. 2010.

[24] El-Sakka, A.I., Tayeb, K.A. "Peyronie's disease in diabetic patients being screened for erectile dysfunction”. J. Urol. 174. 1026-1030. 2005.

[25] Feldman, H.A., Goldstein, I., Hatzichristou, D.G., Krane, R.J., McKinlay, J.B. "Impotence and its medical and psychosocial correlates: results of the Massachusetts Male Aging Study”. J. Urol. 151. 54-61. 1994.

[26] Lu,C., Jiann, B.,Sun C., Lam H., Chih-Hsun Chu, C.,Lee, J. "Association of Glycemic Control with Risk of Erectile Dysfunction in Men with Type 2 Diabetes. ” J. Sex. Med. 6.17191728. 2009.

[27] Yaman O, Akand M, Gursoy A, Erdogan MF, Anafarta K. ”The effect of diabetes mellitus treatment and good glycemic control on the erectile function in men with diabetes mellitus-induced erectile dysfunction: A pilot study”. J. Sex. Med. 3.344-348. 2006.

[28] Hidalgo-Tamola, J., Chitaley, K. "Type 2 Diabetes Mellitus and Erectile Dysfunction”. J. Sex. Med. 4. 916-926. 2009.

[29] Jannini, E.A., Lombardo, F., Lenzi, A. "Correlation between ejaculatory and erectile dysfunction”. Int. J. Androl. 28(Suppl. 2). 40-45. 2005.

[30] Mikailiūkštienė A, Juozulynas A, Narkauskaitė L, Zagminas K, Sąlyga J, Stukas R. "Quality of life in relation to social and disease factors in patients with type 2 diabetes in Lithuania”. Med. Sci. Monit. [Accessed Mar 6, 2013].

[31] Vinik, A.I., Maser, R.E., Mitchell, B.D., et al. "Diabetic autonomic neuropathy”. Diabetes Care 26. 1553-1579. 2003.

[32] Andersson, B., Marin, P., Lissner, L., Vermeulen, A., Bjorntorp, P. "Testosterone concentrations in women and men with NIDDM". Diabetes Care, 17. 405-411. 1994.

[33] Laumann, E. O., Paik, A. \& Rosen, R. C. " Sexual dysfunction in the United States: prevalence and predictors”. JAMA. 10, 281. 537-544.1999.

[34] Masumori, N., Tsukamoto, T., Kumamoto, Y., Panser, L.A., Rhodes, T., Girman, C.J., et al. "Decline of sexual function with age in Japanese men compared with American men - results of two community-based studies”. Urology 54. 335-345. 1999.

[35] Travison, T.G., Araujo, A.B., Morley, J.E., O’Donnell, A.B., McKinlay, J.B. "The relationship between libido and testosterone in aging men: Results from the Massachussetts Male Aging Study”. J. Clin. Endocrinol. Metab. 91. 2509-2513. 2006.

[36] Segraves, R.T. "Management of hypoactive sexual desire disorder”. Adv. Psychosom. Med. 29. 23-32. 2008.

[37] Ellenberg, M., Weber, H. "Retrograde ejaculation in diabetic neuropathy”. Ann. Int. Med. 65. 1237-1246. 1966.

[38] Tefekli, A., Kandirali, E., Erol, B., Tunc, M., Kadioglu, A. "Peyronie's disease: a silent consequence of diabetes mellitus". Asian J. Androl. 8. 75-79. 2006.

[39] Arafa, M., Eid, H., El-Badry, A., Ezz-Eldine, K., Shamloul, R. "The prevalence of Peyronie's disease in diabetic patients with erectile dysfunction”. Int. J. Impotence Res. 19. 213-217. 2007.

[40] El-Sakka, A. I., Selph, C. A., Yen, T. S. B., Dahiya, R. and Lue, T. F. "The effect of surgical trauma on rat tunica albuginea". J. Urol.159. 1700-1707. 1998.

[41] Mondiani, N., Ponchietti, R., Gontera, ., Muir, G.H., Natali, A., Caldarera, E., Biscioni, S., Rizzo, M. ” Penile length is normal in most men seeking penile lengthening procedures”. Int. J. Impot. Res. 14. 283-286. 2002.

[42] Corona, G., Mannucci, E., Petrone, L., Fisher, A.D., Balercia, G., De Scisciolo, G., et al. "Psychobiological correlates of delayed ejaculation in male patients with sexual dysfunctions”. J. Androl. 27. 453-458. 2006.

[43] Rowland, D.L., Keeney, C., Slob, A.K. "Sexual response in men with inhibited or retarded ejaculation”. Int. J. Impotence Res. 16. 270-274. 2004. 
[44] Althof, S., Rosen, R., Symonds, T., Mundayat, R., May, K., Abraham, L. "Development and validation of a new questionnaire to assess sexual satisfaction, control, and distress associated with premature ejaculation”. J. Sex. Med. 3. 465-475. 2006. 